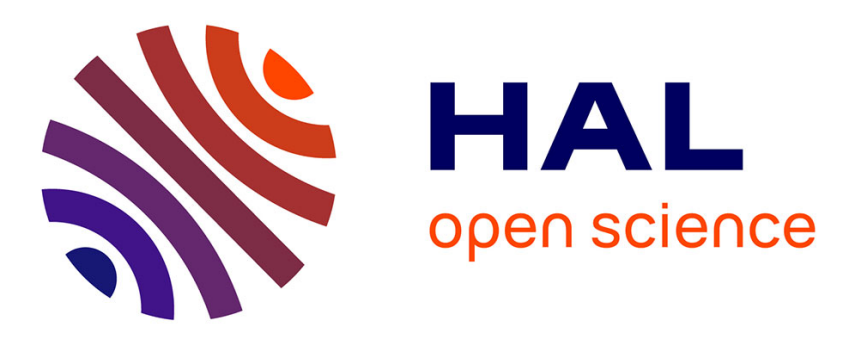

\title{
Cone-Beam Computed Tomography contrast validation of an artificial periodontal phantom for use in endodontics
}

Jerôme Michetti, Adrian Basarab, Michel Tran, Franck Diemer, Denis Kouamé

\section{To cite this version:}

Jerôme Michetti, Adrian Basarab, Michel Tran, Franck Diemer, Denis Kouamé. Cone-Beam Computed Tomography contrast validation of an artificial periodontal phantom for use in endodontics. 37th Annual International Conference of the IEEE Engineering in Medicine and Biology Society (EMBC 2015), Aug 2015, Milano, Italy. pp. 7905-7908. hal-01363373

\section{HAL Id: hal-01363373 \\ https://hal.science/hal-01363373}

Submitted on 9 Sep 2016

HAL is a multi-disciplinary open access archive for the deposit and dissemination of scientific research documents, whether they are published or not. The documents may come from teaching and research institutions in France or abroad, or from public or private research centers.
L'archive ouverte pluridisciplinaire HAL, est destinée au dépôt et à la diffusion de documents scientifiques de niveau recherche, publiés ou non, émanant des établissements d'enseignement et de recherche français ou étrangers, des laboratoires publics ou privés. 


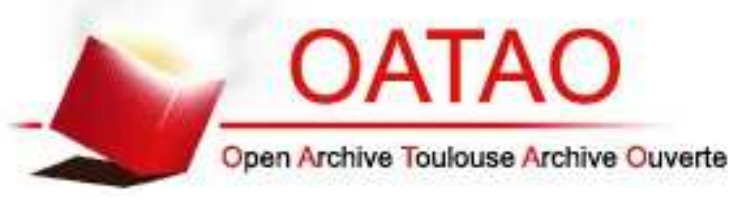

\section{Open Archive TOULOUSE Archive Ouverte (OATAO)}

OATAO is an open access repository that collects the work of Toulouse researchers and makes it freely available over the web where possible.

This is an author-deposited version published in : http://oatao.univ-toulouse.fr/ Eprints ID : 15325

The contribution was presented at EMBC 2015 :

http://embc.embs.org/2015/

To cite this version : Michetti, Jérôme and Basarab, Adrian and Tran, Michel and Diemer, Franck and Kouamé, Denis Cone-Beam Computed Tomography contrast validation of an artificial periodontal phantom for use in endodontics. (2015) In: 37th Annual International Conference of the IEEE Engineering in Medicine and Biology Society (EMBC 2015), 25 August 2015 - 29 August 2015 (Milano, Italy).

Any correspondance concerning this service should be sent to the repository administrator: staff-oatao@listes-diff.inp-toulouse.fr 


\title{
Cone-Beam Computed Tomography contrast validation of an artificial periodontal phantom for use in endodontics
}

\author{
Jérôme Michetti , Adrian Basarab, Michel Tran, Franck Diemer and Denis Kouamé
}

\begin{abstract}
Validation of image processing techniques such as endodontic segmentations in cone-beam computed tomography (CBCT) is a challenging issue because of the lack of ground truth in in vivo experiments. The purpose of our study was to design an artificial surrounding tissues phantom able to provide CBCT image quality of real extracted teeth, similar to in vivo conditions. Note that these extracted teeth could be previously scanned using micro computed tomography $(\mu \mathrm{CT})$ to access true quantitative measurements of the root canal anatomy. Different design settings are assessed in our study by comparison to in vivo images, in terms of the contrast-to-noise ratio (CNR) obtained between different anatomical structures. Concerning the root canal and the dentine, the best design setup allowed our phantom to provide a CNR difference of only $3 \%$ compared to clinical cases.
\end{abstract}

\section{INTRODUCTION}

Recently, cone beam computed tomography (CBCT) is available for dental offices thanks to the reduced costs and dimensions [1,2]. CBCT is an extra-oral imaging system dedicated to explore the whole maxillo-facial or to partially visualize dento-maxillo-facial structures (the field of view varies from $15 \mathrm{~cm}$ to $5 \mathrm{~cm}$ or less) [3]. Unlike conventional CT scans, CBCT has a reduced acquisition time and uses lower irradiation doses. Despite the relatively limited field of view, its spatial resolution is very good in all imaging planes $[4,5]$. CBCT devices give the dental surgeon high-quality three dimensional diagnostic images of the maxillofacial region. Many dental disciplines exploit the potential of CBCT for diagnosis, decisions on therapy and surgical preparation $[6,7,8,9]$. Currently, there is however no application dedicated to endodontics and aimed at exploring the root canal system quantitatively. Endodontics is a dental specialty concerned with the maintenance of the dental pulp in a state of health and with the treatment of the pulp cavity (pulp chamber and root canal). A good knowledge of the root canal anatomy is an indispensable prerequisite to ensure the treatment success of the pulp cavity. Three guidelines are important: to identify and prepare the main canals, to establish and respect working lengths and to assess the initial apical canal diameter in order to allow an adequate preparation size [10]. Quantitative analysis of the root canal on CBCT data requires the segmentation of the endodontic

J. Michetti, A. Basarab and D. Kouamé are with the Toulouse Institute of Computer Science Research, Toulouse, 31062 Cedex 9, France (corresponding author e-mail: jerome.michetti@irit.fr).

J. Michetti, M. Tran and F. Diemer are with the Faculté de Chirurgie Dentaire, Université Paul Sabatier, Toulouse, 31059 Cedex 9, France.

F. Diemer is with the Clément Ader Institute, Toulouse, France. system. The scan limited quality (limited resolution compared to the small size of the root canal anatomy) makes this segmentation process difficult. The comparison of histological sections of the root canal with corresponding CBCT images proved that this imaging system combined with segmentation routines could be an interesting endodontic measurement tool. Existing experiments showing the interest of CBCT in such applications were however undertaken on extracted teeth [11]. Indeed, validation of endodontic segmentations is a challenging issue because of the difficulties to access to the ground truth in in vivo protocols. Exact measurements of the internal anatomy of the teeth need the extraction of the teeth to undertake invasive techniques [11,12] or the use of more powerful imaging system such as micro computed tomography $(\mu \mathrm{CT})$ $[13,14]$. Unfortunately most of the teeth needing extraction are often deteriorated (cavities), with root canal treatment or prosthetics. Intact fully formed teeth have to be extracted for treatment purposes and are often associated to periodontal diseases, which implies an absence of surrounding tissues around the teeth. Moreover, multi-rooted teeth might need root separation to avoid bone damages during the surgery procedure. Due to the radiation protection for the patient [15], consents for research have to be collected and a single CBCT device could be studied in this kind of in vivo protocol, which appears to be complex to implement. With ex vivo protocols, cadaver head from body donation for science or dry skulls and mandibles [16,17] could represent a solution but also encounter specific problems. The risk of destruction of the mandible with the extraction or the use of invasive techniques to obtain real measurements of the root canal system could involve the loss of the samples. To avoid these issues, single rooted teeth are mostly investigated [18]. Nevertheless, other CBCT analyses after extraction by replacing teeth in their sockets, could appear less faithful to the reality due to the gap between teeth and alveolar bone even if it could be filled with Agar-agar or dental wax $[19,20]$. The access to these samples and their use could also be cumbersome. Animal mandibles can also be used to evaluate the performance of CBCT [21], but in the same way with anthropomorphic phantom [22], root canal morphology could be less coherent. In this context, artificial phantom have already been proposed [23,24,25]. For example, Blattner et al. (2010) developed an artificial phantom using real teeth, pig bones and wax to evaluate the ability of CBCT to detect second mesiobuccal canal in maxillary first and second molars [26]. However, no image quality validation of this phantom compared to in vivo conditions was provided. 
In our work, we propose the design of a new phantom dedicated to CBCT image processing applications. In contrast to existing attempts, the purpose of our study is to validate the image quality of this new practical protocol for endodontic phantoms. The reminder of the paper is organized as follows. First, the phantom fabrication protocol and the image acquisition setup are described. Second, an image quality analysis procedure based on contrast-to-noise ratio is proposed in order to compare the quality of the CBCT images acquired on our phantom to those obtained under in vivo conditions. Finally, a discussion and the conclusions are reported in sections IV and V.

\section{MATERIALS AND METHODS}

\section{A. Phantom protocol}

Six different intact freshly extracted teeth (four singlerooted and two multi-rooted teeth) with closed apices were used to design two phantoms. First, 8 layers of light-cured Hybrid Bond (Sun Medical, Japan) were applied on each root in order to simulate a periodontal ligament. Second, the lamina dura, which is a bundle bone i.e. a radio-opaque line adjacent to the periodontal ligament lining the tooth socket, was built on the root surfaces using plaster mixed with water. Two rectangular moulds $(3.5 \mathrm{~cm} \times 1.3 \mathrm{~cm} \times 3.2 \mathrm{~cm})$ were filled with a mixture of $4.5 \mathrm{~g}$ of plaster, $1.5 \mathrm{~g}$ of sawdust, $0.3 \mathrm{~g}$ of sodium alginate (for dental impression, Zelgan Plus, Dentsply, USA) and $9 \mathrm{ml}$ of water to create mimicking trabecular bone. Finally, three prepared teeth were inserted in each mould until the enamel-cement junction. Once the trabecular bone mimicking material hardened, the phantoms were removed from their mould (see Fig. 1). During the acquisition procedure, different sizes of cortical bone simulator (plasterboard) placed around the phantom were investigated. Four different thicknesses of 0.5, 1.0, 1.5 and respectively $2.0 \mathrm{~cm}$ were investigated. For each size of cortical bone simulator, a CBCT acquisition was realized with or without a layer of $1.0 \mathrm{~cm}$ of wax as soft tissue simulator.

\section{B. Acquisitions}

Eight acquisitions were performed for each phantom with a CS 8100 3D scanner (Carestream Health, Rochester, NY, USA) providing a resolution of $75 \mu \mathrm{m}$. The field of view (FOV) was a cylinder of $5 \mathrm{~cm} \times 5 \mathrm{~cm}$ and the acquisitions settings were set at 84 kilovolts and 5 milliamps according to manufacturer suggestions for thin adult.

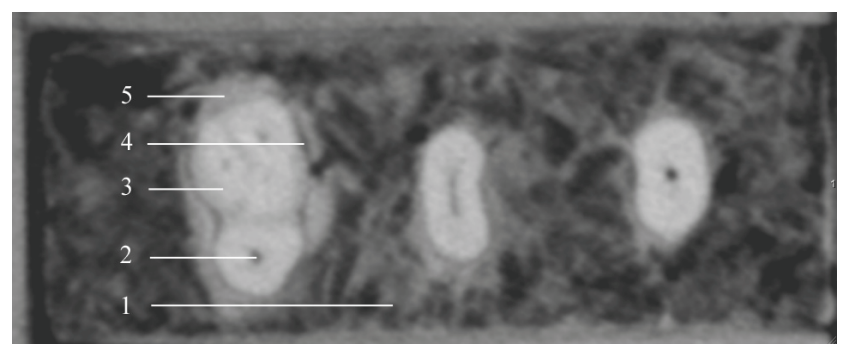

Figure 1. Example of CBCT slice obtained with the phantom developed in this study: 1. Simulated alveolar bone, 2 . Root canal space in the palatine root of a molar, 3. Dentine tissue, 4. Simulated periodontal ligament, 5. Simulated lamina dura.
The control sample was composed of ten teeth (four single-rooted and six multi-rooted teeth), corresponding to four clinical acquisitions collected in dental offices, scanned with the same CBCT device with an equivalent resolution $(75 \mu \mathrm{m})$. These teeth were fully formed, without bone loss or cavities. The acquisitions were initially done for treatment purposes on adjacent teeth and not for the purpose of this particular study.

\section{Image quality analysis}

Three structures were studied using the Mevislab image processing and visualization platform (MeVis Research; Bremen, Germany): the root canal space, the dentine (hard tissue of the roots) and the lamina dura. To avoid inclusion of neighboring tissue in our segmentation, several small regions of interest $(4 \times 4 \times 3$ voxels) were manually placed in different axial reconstructions of each tooth to compose an accurate mask of the desired tissue (10 to 100 regions of interest per mask). For each mask corresponding to the three anatomical structures considered, the mean $(\mu)$ and the variance $\left(\sigma^{2}\right)$ of the voxel grey values were computed. This procedure and these measurements were carried out for the teeth from in vivo acquisitions and for each tooth of the two phantoms for each size of cortical bone simulator with or without the layer of wax. To evaluate the image quality, the contrast-to-noise ratio (CNR) was calculated between the dentine $(\delta)$ and the root canal space $(\chi)$ and between the dentine and the lamina dura (real tissue for in vivo acquisitions and tissue-equivalent substitute for our phantom) $(\chi)(1)$.

$$
\mathrm{CNR}=\frac{\mu_{\delta}-\mu_{\chi}}{\sqrt{\sigma_{\delta}^{2}+\sigma_{\chi}^{2}}}
$$

CNR differences (in percentage) were calculated between the results from the different sizes and structures of the phantom with the mean value of the CNRs computed from the teeth clinical cases. Denoting by $\mathrm{CNR}_{\mathrm{p}}$ and $\mathrm{CNR}_{\mathrm{iv}}$ the measurements obtained with our phantom and respectively the mean CNR value obtained under in vivo conditions, the differences reported in Table I are calculated as follows:

$$
\text { Difference }=\frac{\mathrm{CNR}_{p}-\mathrm{CNR}_{i v}}{\mathrm{CNR}_{i v}} \times 100
$$

\section{RESULTS}

For the teeth from clinical acquisitions, the mean of the CNRs between dentine and canal was 5.78 (with a maximum value of 7.39 and a minimum of 4.18). The mean of the CNRs between dentine and lamina dura was 1.56 (with a maximum of 2.63 and a minimum of 0.55 ).

For the CNR between dentine and canal which evaluates the impact of surrounding conditions on the image of two real anatomical structures, three configurations of our phantom provided a mean value belonging to the interval 
min-max of the in vivo conditions. $1.5 \mathrm{~cm}$ of plaster and 1.0 $\mathrm{cm}$ of wax showed a CNR of $6.57 \pm 1.25,14 \%$ higher compared to the clinical acquisitions. Phantoms built with $2.0 \mathrm{~cm}$ of plaster without and with $1.0 \mathrm{~cm}$ of wax presented a CNR of $5.62 \pm 1.56$ and respectively $4.97 \pm 0.48,3$ and respectively $14 \%$ lower compared to the clinical acquisitions, corresponding to CNRs of (see Table I). Fig. 2 highlights the image degradation for the considered phantom designs compared to two clinical images.

A reduction of the CNR between dentine and lamina dura simulator was shown with the increase of surrounding material size. $2.0 \mathrm{~cm}$ of plaster with $1.0 \mathrm{~cm}$ of wax around the phantom allowed us to obtain the closest CNR $(2.97 \pm 0.79)$ to the in vivo conditions $(90 \%)$ (see Table I).

\section{DISCUSSION}

Phantoms need validation with clinical images before their use to evaluate imaging performance of a CBCT device for a specific clinical purpose. To reach a corresponding image quality, anthropomorphic phantoms provide tissueequivalent substitutes with an attenuation coefficient, a size and a form equivalent to real anatomic structures. However, root canal morphology and its variability could not be mimicked. Only a simplified version of each type of teeth is present $[22,27,28]$. Besides, if the inclusion of teeth to represent various morphology and all clinical situations was possible, that would involve the use of numerous anthropomorphic phantoms, which could be time consuming and very expensive. In artificial phantom, easy use and cheap materials could be used around real teeth to mimic the effect of periodontal tissues and soft tissues on X-ray beam. However, the effect on X-ray beam might be different according to the size of these materials. In our study, the increase of the thickness of the cortical bone substitute and the use of a soft-tissue simulator involved a reduction of the CNR between dentine and root lamina dura. De Molon et al. showed equivalent results by comparing different thickness of soft-tissue simulators on dental and bone densities [29]. A significant influence on the density-level in alveolar bone but not in dental tissues was observed. However, the contrast in our phantom between dentine and lamina dura remains higher than for in vivo conditions. Even if the results for 2.0 $\mathrm{cm}$ of plaster and $1.0 \mathrm{~cm}$ of wax seem close to the variability of clinical acquisitions, further improvements are still necessary.

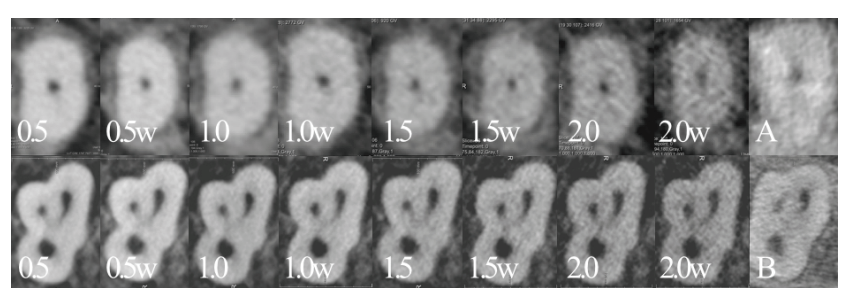

Figure 2. Phantoms built with 0.5 to $2.0 \mathrm{~cm}$ of plaster without or with 1.0 $\mathrm{cm}$ of wax (w). First row: single rooted tooth with the in vivo reference "A". Second row: multi-rooted tooth with the in vivo reference "B".
TABLE I. Phantom Image Quality Results

\begin{tabular}{|cc|cc|cc|}
\hline \multirow{2}{*}{ Size (cm) } & \multicolumn{4}{c|}{ CNR } \\
\cline { 3 - 6 } & & \multicolumn{2}{|c|}{ Dentine - Canal } & \multicolumn{2}{c|}{ Dentine - Lamina dura } \\
\hline \multirow{2}{*}{ Plaster } & Wax & Mean (SD) & Difference & Mean (SD) & Difference \\
\hline 0.5 & 0.0 & $9.71(3.17)$ & $68 \%$ & $5.94(1.48)$ & $281 \%$ \\
0.5 & 1.0 & $9.68(2.62)$ & $68 \%$ & $5.60(1.39)$ & $259 \%$ \\
1.0 & 0.0 & $8.60(2.55)$ & $49 \%$ & $5.20(1.71)$ & $234 \%$ \\
1.0 & 1.0 & $8.12(2.22)$ & $40 \%$ & $5.04(1.19)$ & $223 \%$ \\
1.5 & 0.0 & $7.77(1.22)$ & $34 \%$ & $4.70(1.30)$ & $202 \%$ \\
1.5 & 1.0 & $6.57(1.25)$ & $14 \%$ & $4.17(1.25)$ & $167 \%$ \\
2.0 & 0.0 & $5.62(1.56)$ & $-3 \%$ & $3.61(0.83)$ & $132 \%$ \\
2.0 & 1.0 & $4.97(0.48)$ & $-14 \%$ & $2.97(0.79)$ & $90 \%$ \\
\hline
\end{tabular}

In particular, the thickness of the trabecular bone substitute, which appears larger than for in vivo conditions could be tested. A reduction of the contrast between dentine and root canal system is also observed when the surrounding materials increase (see Fig. 2). A thickness of 2 to $3 \mathrm{~cm}$ of materials around the trabecular substitute provides a CNR similar to teeth from clinical acquisitions. The reduction of the CNR was more important when the size of the phantom exceed the FOV $(5 \mathrm{~cm})$. Indeed, Araki et al. found that pixel value in CBCT might be affected by various conditions such as the presence of surrounding materials outside the FOV [30]. The results of our study are obviously dependent on the CBCT device and settings we used. The same phantom in other acquisition conditions might provide different results. FOV, voxel sizes and number of analyzed images could also affect the phantom image quality [16,31] and involve the need of different sizes of tissue-equivalent substitutes to be correlated with clinical images. The reproducibility of the manufacture of this artificially periodontal phantom would remain to assess and a larger sample of clinical cases would provide a better representation of the distribution of the CNRs in vivo. Nevertheless, our results show that with a simple protocol and with easy-to-find materials, the manufacture of a periodontal phantom around real teeth provides image contrast similar to in vivo conditions for use in endodontics.

\section{CONCLUSION}

Our artificial periodontal phantom with $2.0 \mathrm{~cm}$ of plaster as cortical bone substitute, with or without soft-tissue simulator, is able to provide CBCT extracted teeth images similar to in vivo conditions. With an easy protocol, the validation of image processing techniques for clinical purpose, such as endodontic segmentation, could be undertaken on extracted real teeth. Moreover, these teeth could be previously scanned with $\mu \mathrm{CT}$ to provide ground truth of the root canal system. 


\section{REFERENCES}

[1] S. Patel, "New dimensions in endodontic imaging: part 2 - cone beam computed tomography," Int Endod J, vol. 42, 2009, pp. 463-475.

[2] A. Nemtoi, C. Czink, D. Haba, A. Gahleitner, "Cone beam CT: a current overview of devices," Dentomaxillofac Radiol, vol. 42, 2013, 20120443.

[3] W. C. Scarfe, D. L. Martin, D. Gane, A. G. Farman, "Use of cone beam computed tomography in endodontics," Int J Dent , 2009, 634567:1-20

[4] A. Winter, A. Pollack, H. Frommer, L. Koenig, "Cone beam volumetric tomography vs. medical CT scanners," N Y State Dent J, vol. 71, 2005, pp. 28-33.

[5] M. K. Nair, U. P. Nair, "Digital and advanced imaging in endodontics: a review," J Endod, vol. 7, 2007, PP. 1-6.

[6] T. Cotton, T. Geisler, D. Holden, S. Schwartz, "Endodontic applications of cone beam volumetric tomography, "J Endod, vol. 33, 2007, pp. 1121-32.

[7] T. Tsurumachi, K. Honda, "A new cone beam computerized tomography system for use in endodontic surgery," Int Endod J, Vol. 40, 2007, pp. 224-32.

[8] S. Patel, A. Dawood, "The use of cone beam computed tomography in the management of external cervical resorption lésions," Int Endod J, vol. 40, 2007, pp. 730-7.

[9] S. Patel, A. Dawood, T. Pitt Ford, E. Whaites, "The potential applications of cone beam computed tomography in the management of endodontic problems," Int Endod J, vol. 40, 2007, pp. 813-30.

[10] O. A. Peters, "Current challenges and concepts in the preparation of root canal systems: a review," J Endod, vol. 40, 2004, pp. 559-67.

[11] J. Michetti, D. Maret, J-P. Mallet, F. Diemer, "Validation of conebeam computed tomography as a tool to explore root canal anatomy," J Endod. Vol. 36, 2010, pp. 1187-90.

[12] J. S. Rhodes, T. R. Ford, J. A. Lynch, P. J. Liepins, R. V. Curtis, "Micro-computed tomography: a new tool for experimental endodontology," Int Endod J, vol. 32, 1999, pp. 165-70.

[13] Y. Liu, R. Olszewski, E. Alexandroni, R. Enciso, T. Xu, J. Mah, “The validity of in vivo tooth volume determinations from cone-beam computed tomography," Angle Orthod, vol. 80, 2010, pp. 160-166.

[14] D. Maret, F. Molinier, J. Braga, O. A. Peters, N. Telmon, J. Treil, J. M. Inglèse, A. Cossié, J. L. Kahn, M. Sixou, "Accuracy of 3D Reconstructions Based on Cone Beam Computed Tomography," J Dent Res, vol. 89, 2010, pp. 1465-1469.

[15] "Basic principles for use of Dental CBCT," Consensus guidelines of the European academy of dental and maxillofacial radiology, 2009.

[16] N. Ibrahim, A. Parsa, P. van der Stelt, I. H. A. Aartman, D. Wismeijer, "The effect of scan parameters on cone beam CT trabecular bone microstructural measurements of the human mandible," Dentomaxillofac Radiol, vol. 42, 2013, 20130206.

[17] Y. -H. Liang, L. Jiang, X. -J. Gao, H. Shemesh, P. R. Wesselink, M. $-\mathrm{K}$. Wu, "Detection and measurement of artificial periapical lesions by cone-beam computed tomography," Int Endod J, vol. 47, 2014, pp. 332-338.

[18] K. Kamburoğlu, S. Murat, E. Kolsuz, H. Kurt, S. Yüksel, C. Paksoy, "Comparative assessment of subjective image quality of crosssectional cone-beam computed tomography scans," Journal of Oral Science, vol. 53, 2011, pp. 501-508.

[19] B. Hassan, M. E. Metska, A. R. Ozok, P. van der Stelt, P. R. Wesselink, "Detection of vertical root fractures in endotdontically treated teeth by a cone beam computed tomography scan," $J$ Endod, vol. 35, 2009, pp. 719-722.

[20] M. C. C. Nascimento, Y. Nejaim, S. M. de Almeida, F. N. Bòscolo, F. Haiter-Neto, L. C. Sobrinho, E. J. N. L. Silva, "Influence of cone beam CT enhancement filters on diagnosis ability of longitudinal root fractures," Dentomaxillofac Radiol, vol. 43, 2014, 20130374.

[21] S. A. Esposito, B. Huybrechts, P. Slagmolen, E. Cotti, W. Coucke, R. Pauwels, P. Lambrechts, R. Jacobs, "A novel method to estimate the volume of bone defects using cone-beam computed tomography: an in vitro study," J Endod, vol. 39, 2013, pp. 1111-1115.

[22] Atom max dental and diagnostic head phantom (model 711-HN), CIRS Tissue Simulation \& Phantom Technology, http://www.cirsinc.com/products/all/35/atom-max-dental-anddiagnostic-head-phantom/
[23] Y. -H. Liang, M. Yuan, G. Li, H. Semesh, P. R. Wesselink, M. -K. $\mathrm{Wu}$, "The ability of cone-beam computed tomography to detect simulated buccal and lingual recesses in root canals," Int Endod $J$, vol. 45, 2012, pp. 724-729.

[24] C. Lucena, J. M. López, J. A. Martín, V. Robles, M. P. GonzálezRodríguez, "Accuracy of working length measurement: electronic apex locator versus cone-beam computed tomography," Int Endod $J$, vol. 47, 2014, pp.246-256.

[25] B. Bechara, C. Alex McMahan, W. S. Moore, M. Noujeim, F. B. teixeiras, H. Geha, "Cone beam CT scans with and without artefact reduction in root fracture detection of endodontically treated teeth," Dentomaxillofac Radiol, vol. 42, 2013, 20120245.

[26] T. C. Blattner, N. George, C. C. Lee, V. Kumar, C. D. J. Yelton, "Efficacy of cone-beam computed tomography as a modality to accurately identify the presence of second mesiobuccal canals in maxillary first and second molars: a pilot study," J Endod, vol. 36, 2010 , pp. $867-870$

[27] J-T. Ho, J. Wu, H-L. Huang, M. YC. Chen, L-J. Fuh, J-T. Hsu, "Trabecular bone structural parameters evaluated using dental conebeam computed tomography: cellular synthetic bones," Biomed Eng Online, vol. 12, 2013, 115 .

[28] J. F. Winslow, D. E. Hyer, R. F. Fisher, C. J. Tien, D. E. Hintenlang, "Construction of anthropomorphic phantoms for use in dosimetry studies," J Appl Clin Med Phys, vol. 10, 2009, 3:2986.

[29] R. S. de Molon, R. G. Batitucci, R. Spin-Neto, G. M. Paquier, C. E. Sakakura, G. M. Tosoni, G. Scaf, "Comparison of changes in dental and bone radiographic densities in the presence of different soft-tissue simulators using pixel intensity and digital subtraction analyses," Dentomaxillofac Radiol, vol. 41, 2013, 20130235.

[30] K. Araki, T. Okano, "The effect of surrounding conditions on pixel value of cone beam computed tomography," Clin Oral Implants Res, vol. 24, 2013, pp. 862-865.

[31] B. Bechara, C. A. McMahan, W. S. Moore, M. Noujeim, H. Geha, F. B. teixeira, "Contrast-to-noise ratio difference in small field of view cone beam computed tomography machines," vol. 54, J Oral Sci, pp. $227-232$. 